دراسة تأثير مواد التعبئة ومدة الخزن في الخواص الريولوجية للطحين

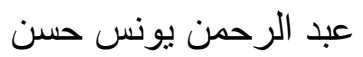 \\ الثركة العامة لتصنيع الحبوب/ لئنينوى
}

\author{
صبيحة حسين الجبوري

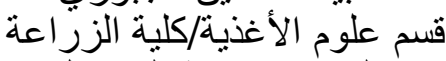

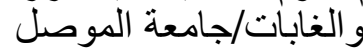

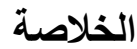

تم دراسة الخواص الريولوجية لطحين الحنطة المعبأ في نوعين من أكياس التعبئة هما أكياس

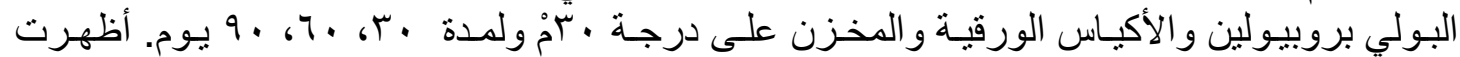

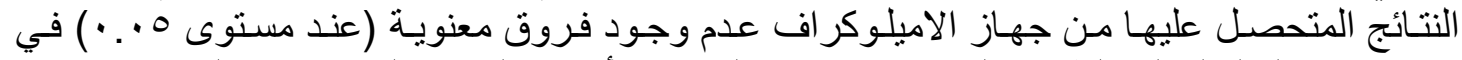

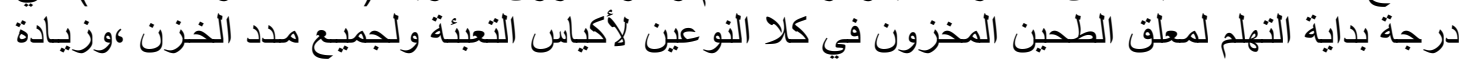

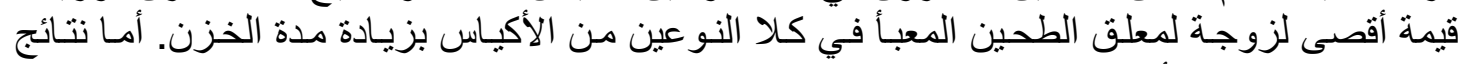

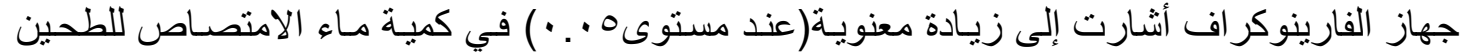

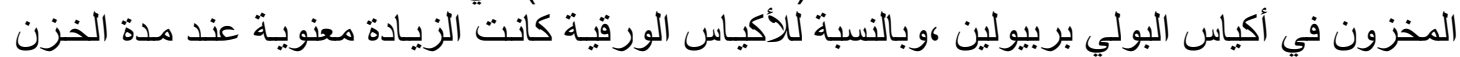

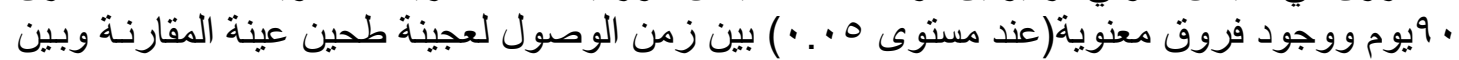

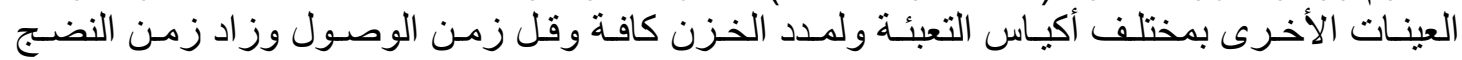

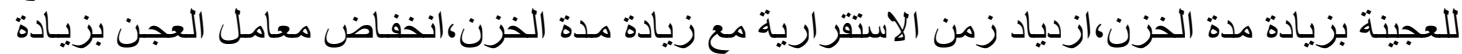

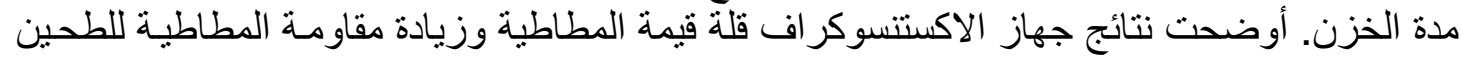

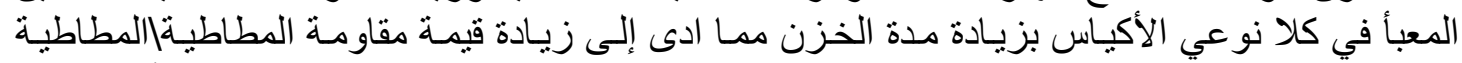

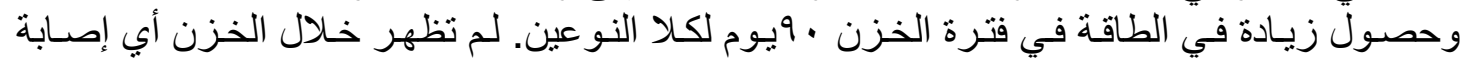

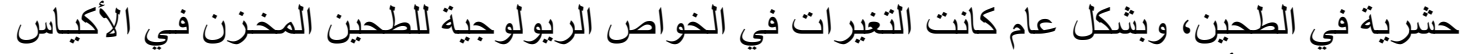
الورقية اقل من أكياس البولي بربيولين.

\section{المقدمسة}

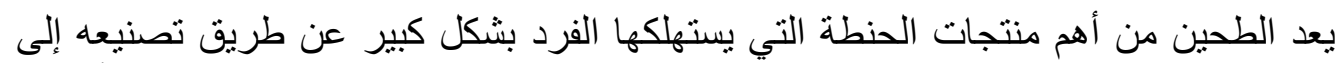

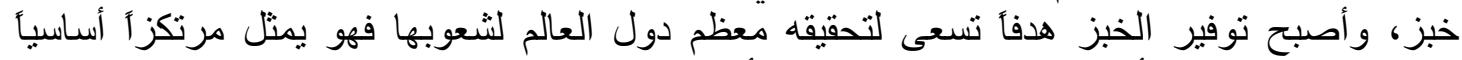

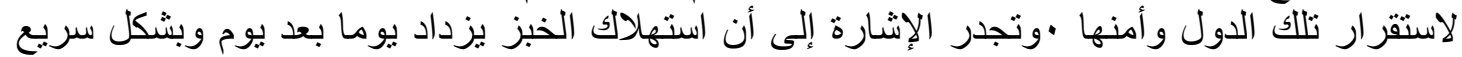

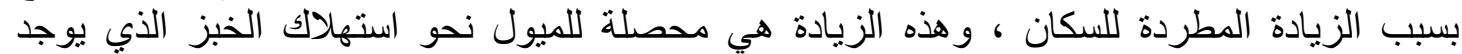

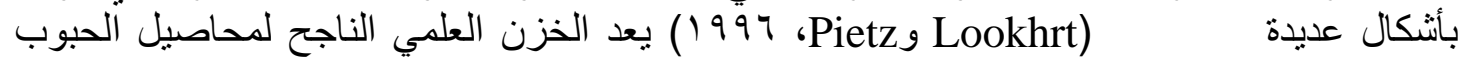

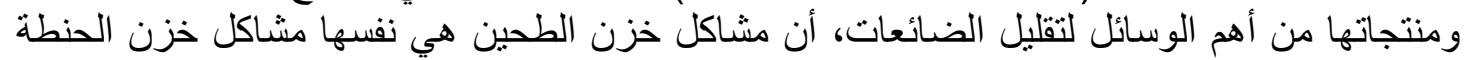

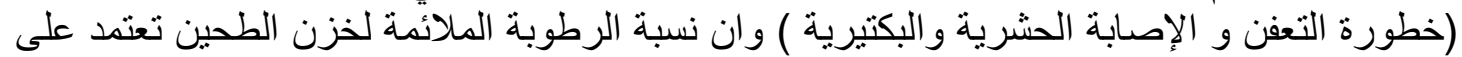

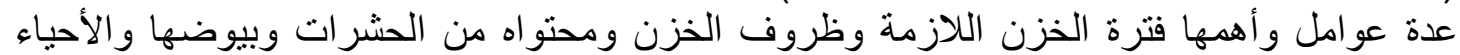

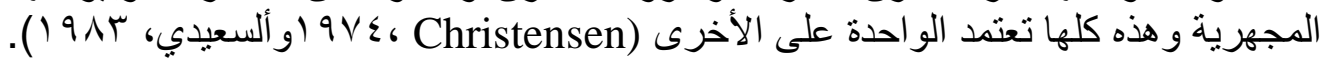

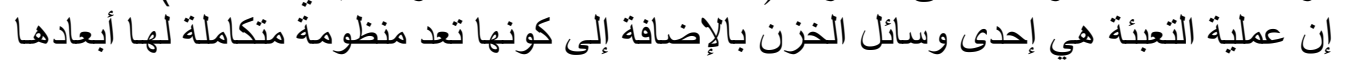

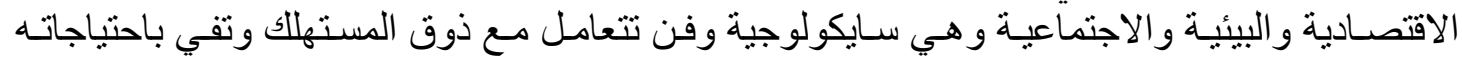

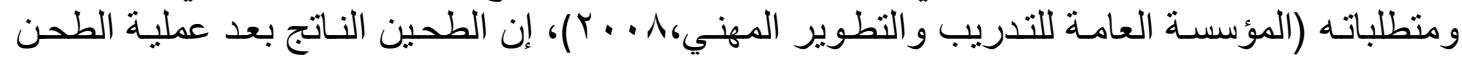

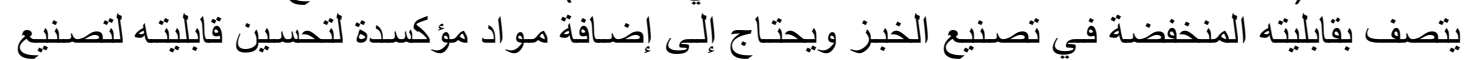

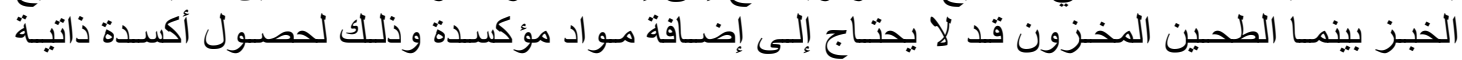

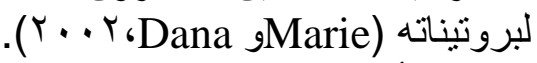

أجريت العديد من الدراسات حول أسلوب الخزن والتعبئة وكذلك على تأئزر المادة كيميائيً

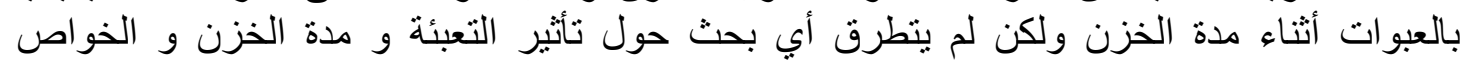

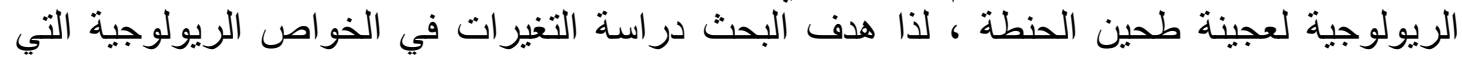
تحصل في طحين الحنطة الدخزن لمدد مختلفة ولنو عين من أكياس التعبئة. 


\section{مواد البحث وطرائقه}

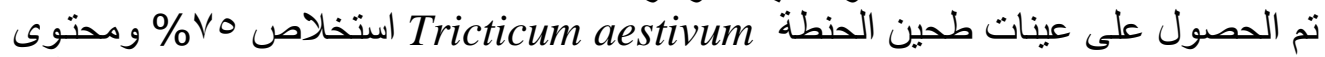

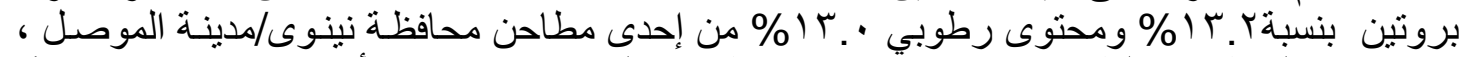

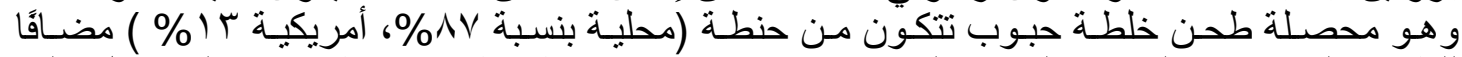

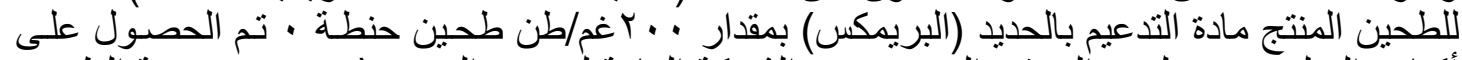

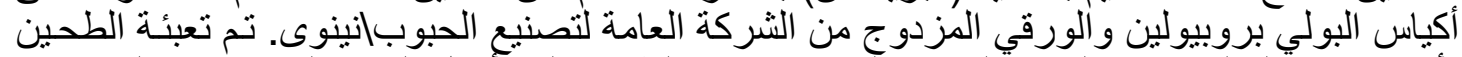

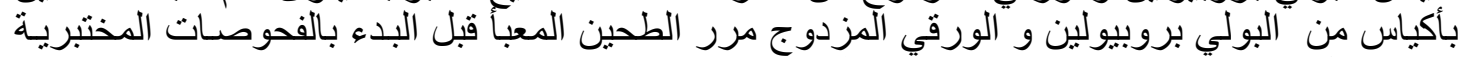

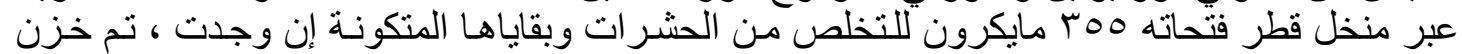

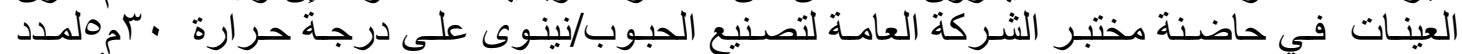

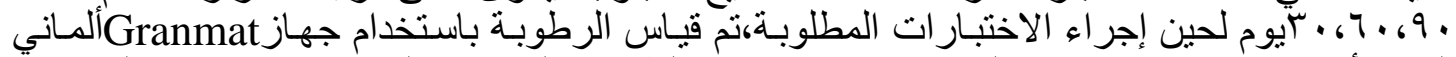

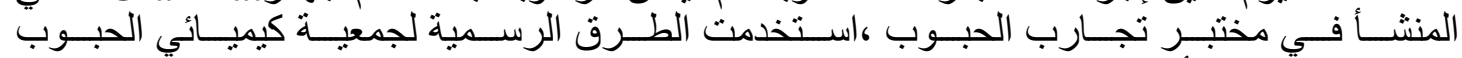

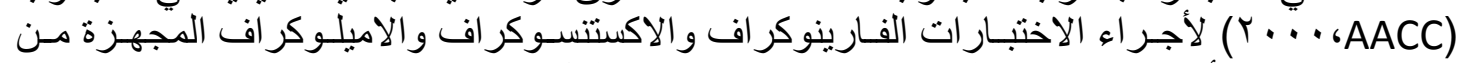

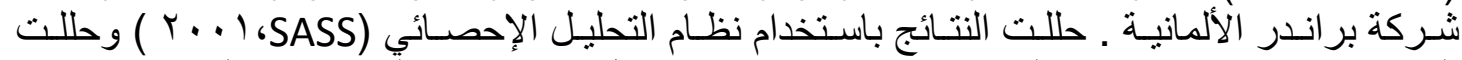
النتائج باستخدام اختبار LSD التي تم استخدامها لاستخر اج اقل فرق معنوي لَّتوسطات النتائج.

\section{النتائج والمناقشة التشات}

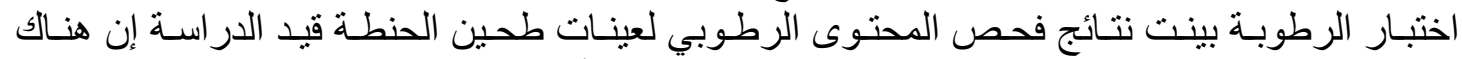

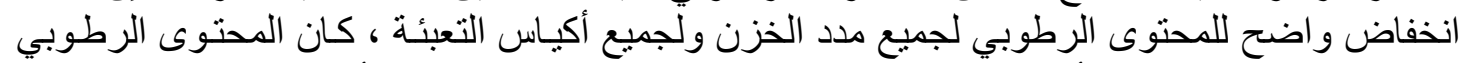

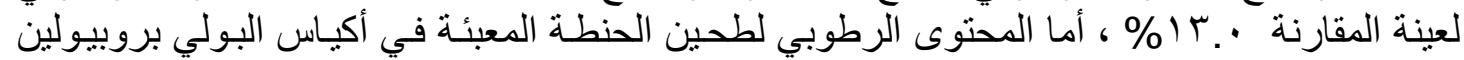

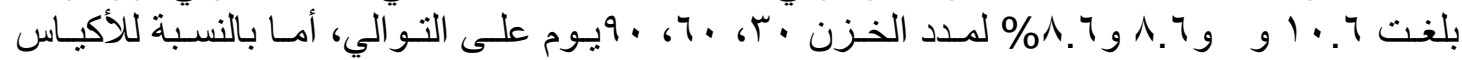

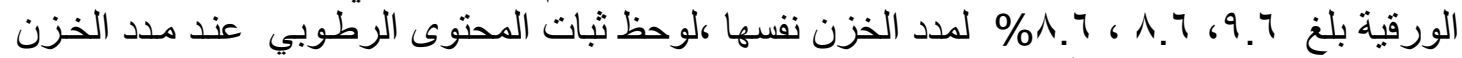

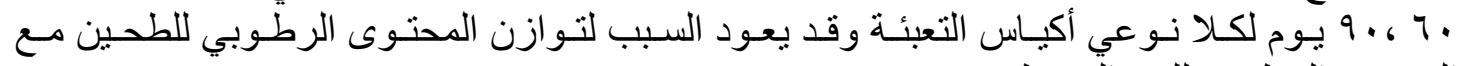

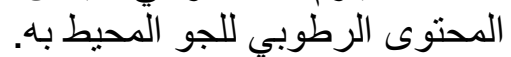

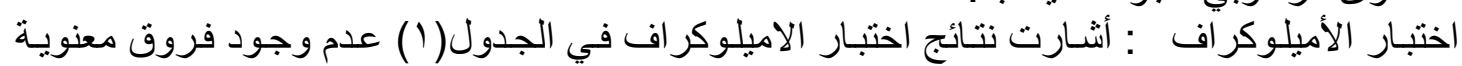

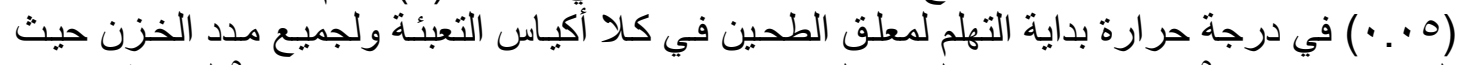

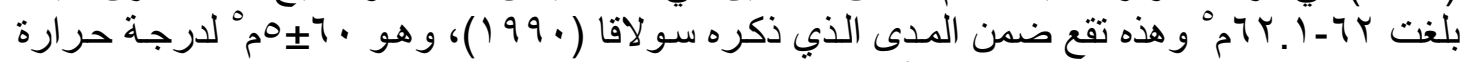

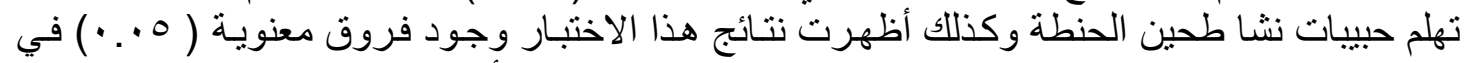

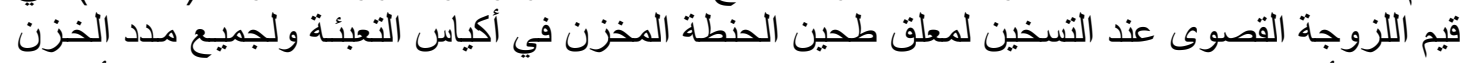

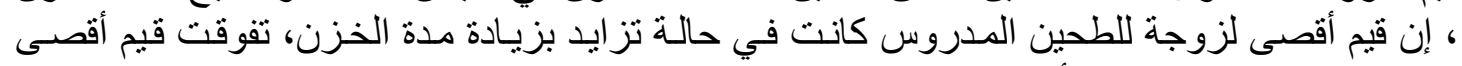

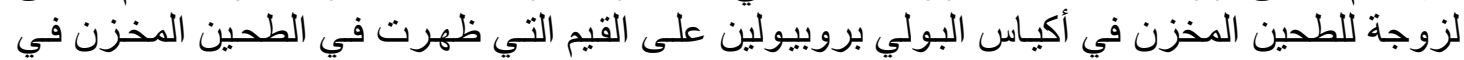

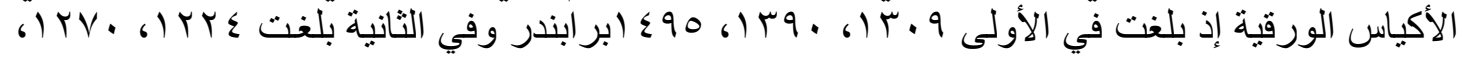

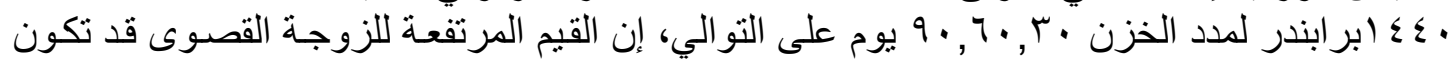

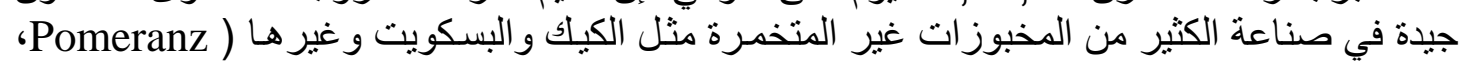

الجدول ( 1 ) : خو اص معلق طحين الحنطة المقاسة بجهاز الأميلوكر اف.

\begin{tabular}{|c|c|c|c|}
\hline اللزوجة القصوى عند نهاية & درجة حرارة التهلم & فترة الخزن & القراءات \\
\hline$j 11 \leqslant V$ & ITr.. & صفر & عينة المقارنة \\
\hline (1T.9 & ITY.l & $r$ & \multirow{3}{*}{ بولي بروبيولين } \\
\hline ج & ITr.. & 7. & \\
\hline i $1 \leqslant 90$ & ITr.l & 9. & \\
\hline g IYYE & ITr.l & $r \cdot$ & \multirow{3}{*}{ ورقيــة } \\
\hline هـ I I . & I Tr.. & 7. & \\
\hline ب ا ب . & I Tr.. & 9. & \\
\hline
\end{tabular}




\section{الأحرف المتشابهة عموديا لا تختلف معنويا عند مستوى (}

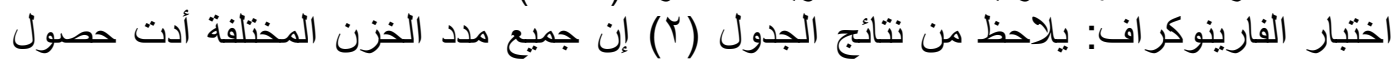

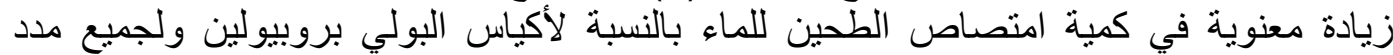

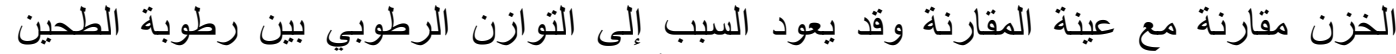

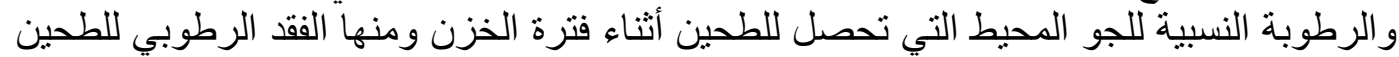

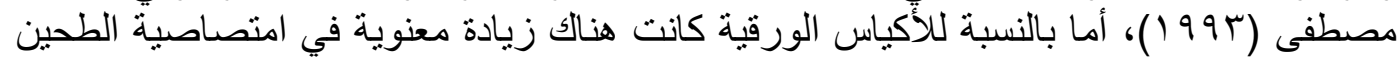

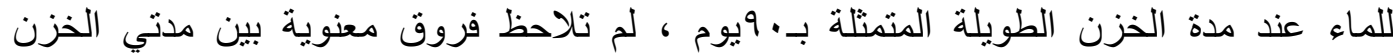
• او • آيوم بالنسبة لهذه الصفة ، بصورة عامة كانت هناك زيادة في في امتصاصية الطحين للماء

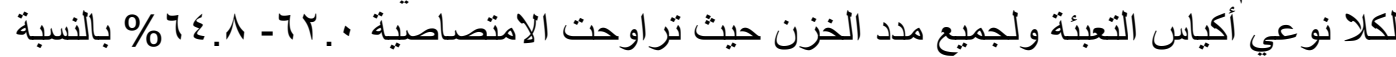

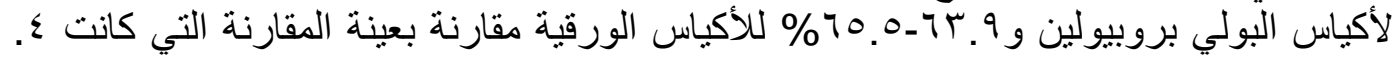

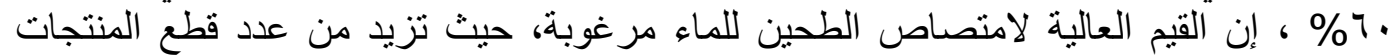

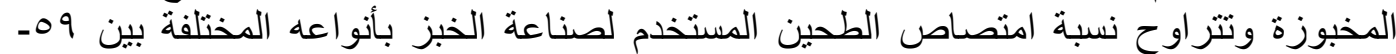

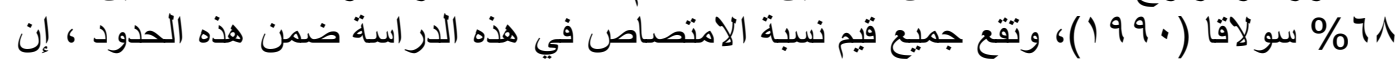

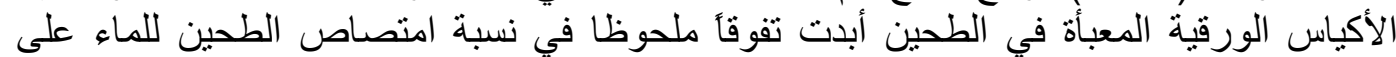

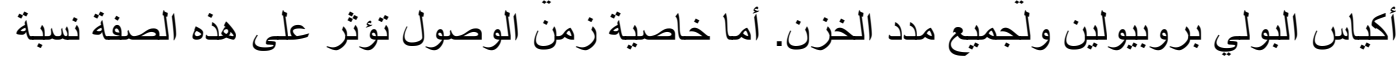

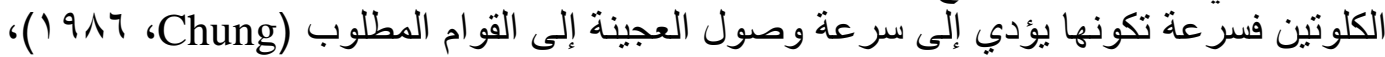

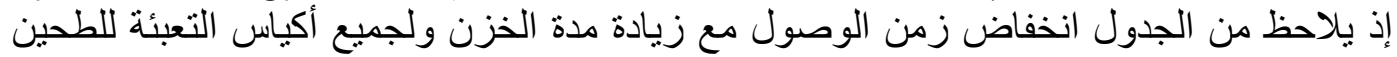

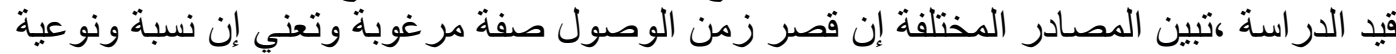

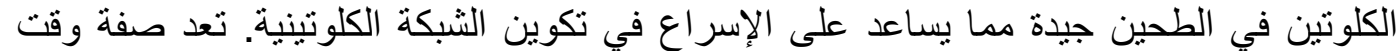

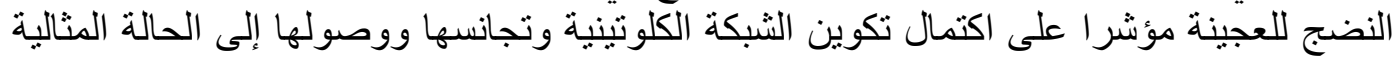

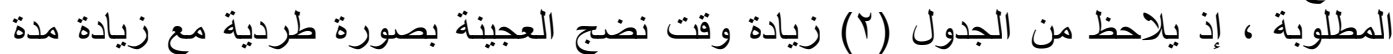

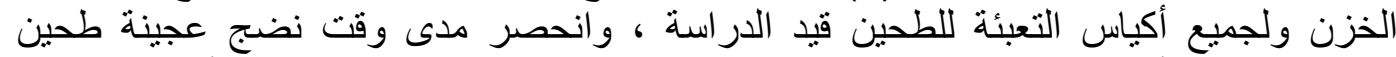

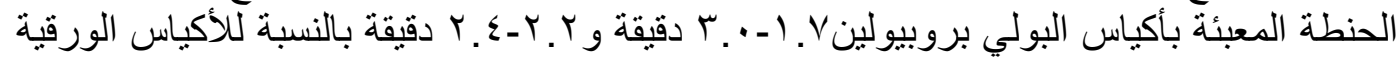

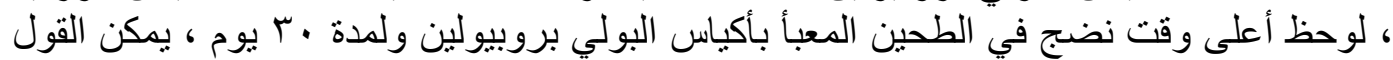

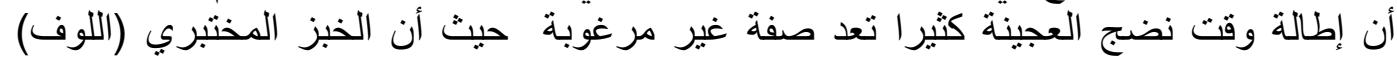

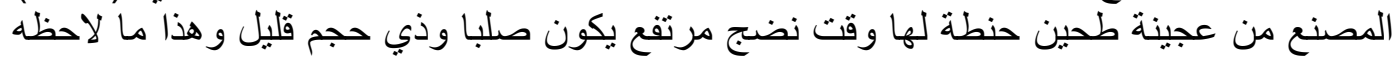

() ( 914 .Chung)

الجدول ( r ) : الصفات المقاسة بجهاز الفارينو غر اف لطحين الحنطة

\begin{tabular}{|c|c|c|c|c|c|c|}
\hline 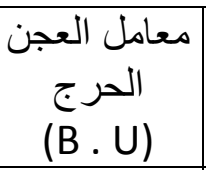 & الاستقرارية زمن & زمن النضةج) & الوصنول & الامتصاصية & الخزن & اكياس التعبنتة \\
\hline أ & 911.1 & ج.0 & ج Y. & 97.5 & صفر & عينة المقارنة \\
\hline ب & كـ & 1. ه ب ج & IT.. & ه.. & $r$. & \multirow{3}{*}{ بولي بروبيولين } \\
\hline ب & 210 & $7^{0.7}$ & ג. 1. & ב ב.V & 7. & \\
\hline . & ج & ج $^{0.7}$ & ج I.V & أب أب أب & 9. & \\
\hline $21 \wedge$ & ج 17.7 & 1. 0. ب ج & r. & 9.7 ج د & $r$. & \multirow{3}{*}{ ورقيـــة } \\
\hline • ק ב & ب IV.0 & آ أب & r.r & بـ & 7. & \\
\hline IV & I11 & 17.0 & ب & 170.0 & 9. & \\
\hline
\end{tabular}

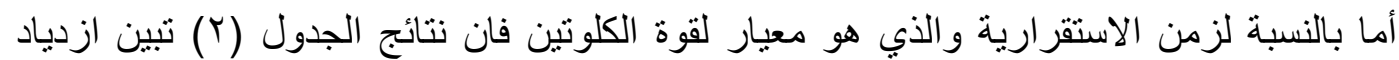

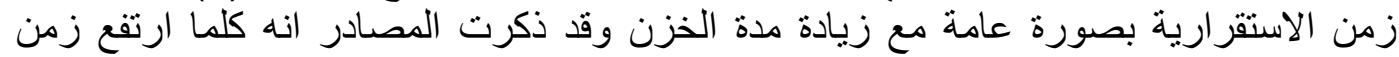

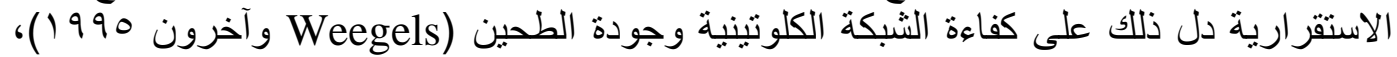
وتبين نتائج الجدول وجود فروق معنوية بين طحين المقارنة وبين العينات الأخرى لمختلف أكياس 


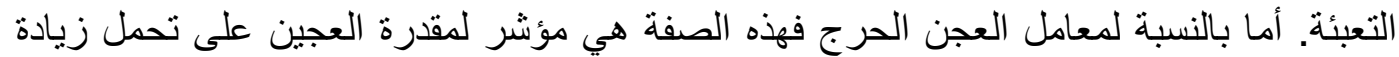

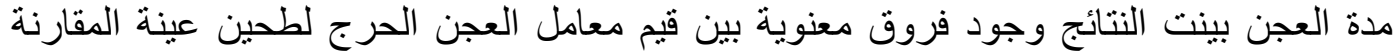

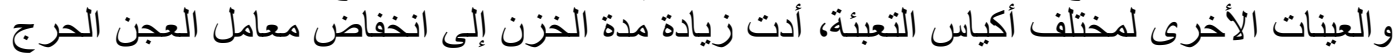

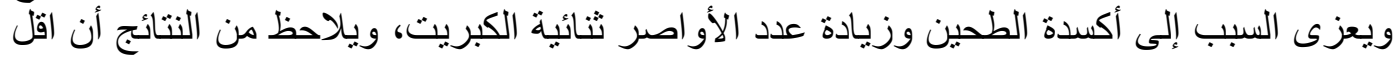

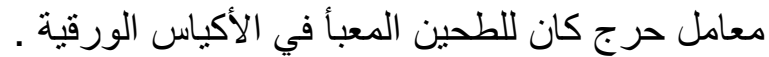

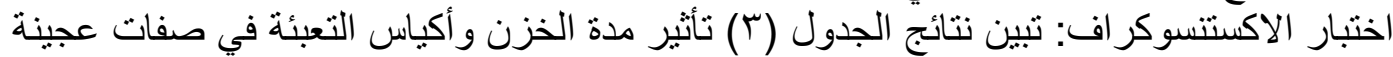

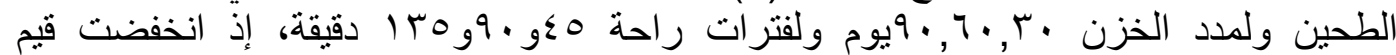

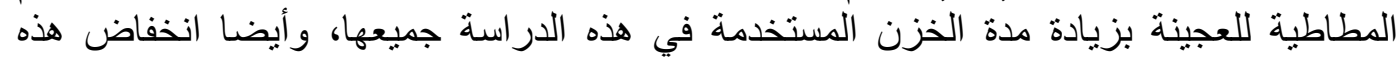

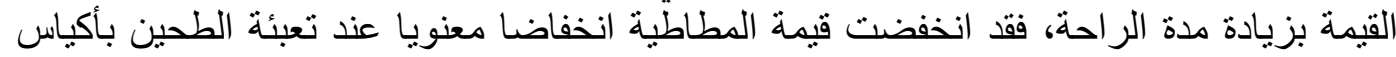

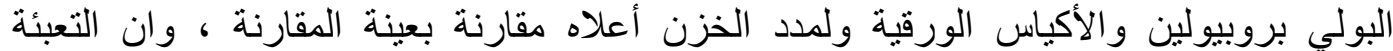

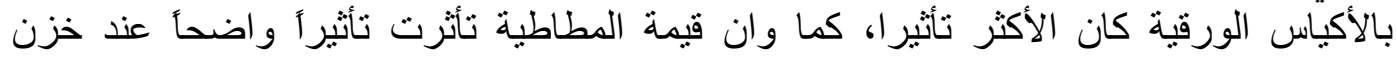

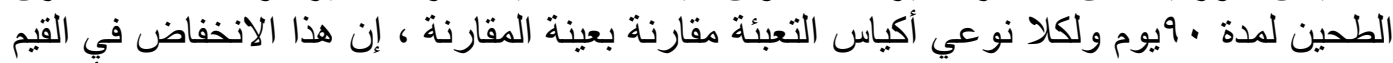

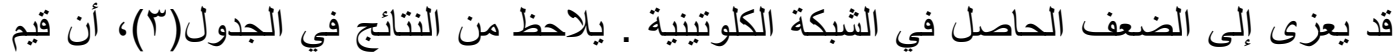

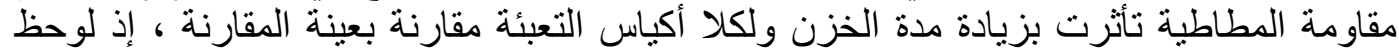

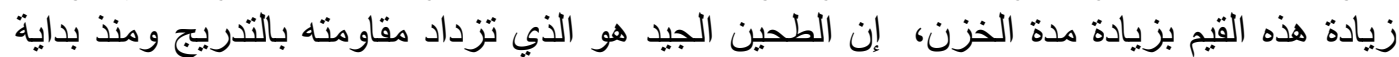

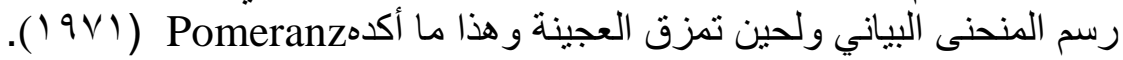

الجدول (T) : خواص عجين طحين الحنطة المقاسة بجهاز الأكستينسوكر اف

\begin{tabular}{|c|c|c|c|c|c|c|}
\hline (سمץ) & مقاومةالمطاطية & |مقاومة المطاطية & المطاطية & فترة الر احة & الخزن & لو القراءات الأكياس \\
\hline$b \wedge \wedge$ & 21.r & ST TYT & $\mid\{\}$. & $\leqslant 0$ & \multirow{3}{*}{ صفر } & \multirow{3}{*}{ عينة مقارنة } \\
\hline$J \wedge 9$ & إ. & b YTV & ب119 & 9. & & \\
\hline ل ك ل & أع & ror & r/ג ج & 1ro & & \\
\hline$\tau^{9 r}$ & 1.9 & jrrq & $2|V|$ & $\leqslant 0$ & \multirow{3}{*}{ r. } & \multirow{9}{*}{ بروبيولين } \\
\hline 1.1 נج & $\tau^{Y .1}$ & $g-r \leqslant V$ & واهـ & 9. & & \\
\hline r ا هـ د & JY. & j j & $917 \varepsilon$ & $11 \% 0$ & & \\
\hline ي ط ي & $\tau^{Y .1}$ & q و وز & $j 109$ & $\leqslant 0$ & \multirow{3}{*}{7.} & \\
\hline$\tau^{9 r}$ & j & . . & $\tau^{100}$ & 9. & & \\
\hline ك & $j r . r$ & • ס دهـ و & b $10 Y$ & $11 \% 0$ & & \\
\hline r |' ج د & gr.o & ج To & $2^{107}$ & $\leqslant 0$ & \multirow{3}{*}{9.} & \\
\hline 1110 & ج". & $\mid \leq 7$. & ح & 9. & & \\
\hline •l إب ج & r. & $i \leqslant V$. & 5 $1 \leqslant 0$ & $1 \% 0$ & & \\
\hline آ ي ط & s $1 . \wedge$ & $\tau^{\mu \cdot V}$ & هـ $17 V$ & $\leqslant 0$ & \multirow{3}{*}{ r. } & \multirow{9}{*}{ ورقية } \\
\hline$\tau^{j q \varepsilon}$ & $\rightarrow r . \wedge$ & ج.0 & 5 $1 \leq \varepsilon$ & 9. & & \\
\hline 291 & $\rightarrow r . \wedge$ & ج & S $1 \leqslant r$ & $11 \% 0$ & & \\
\hline$j 97$ & $j r . r$ & د M TO0 & $2^{107}$ & $\leqslant 0$ & \multirow{3}{*}{7.} & \\
\hline ع ·1 دج & ج". & ب & 5 $1 \leq \varepsilon$ & 9. & & \\
\hline 21.0 & 24.9 & ج & J JV & $1 \% 0$ & & \\
\hline$j \tau^{9 \varepsilon}$ & jr.r & 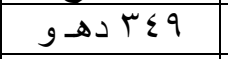 & $\tau^{100}$ & $\leqslant 0$ & \multirow{3}{*}{9.} & \\
\hline 1.9 & د. Y. & I $\leqslant$ TO & 1 1 19 & 9. & & \\
\hline 21.0 & Ir.r & $1 \leqslant 79$ & ك & 1ro & & \\
\hline
\end{tabular}

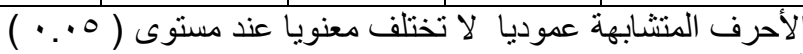

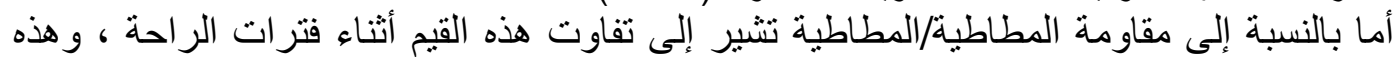
الصفة نشير لقدرة العجين على الاحتفاظ بالغاز ، إذ بينت النتائج من الجدول ذأنة ذاته والأشكال العائدة

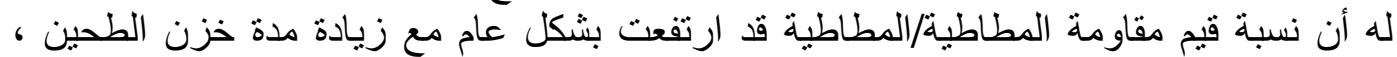

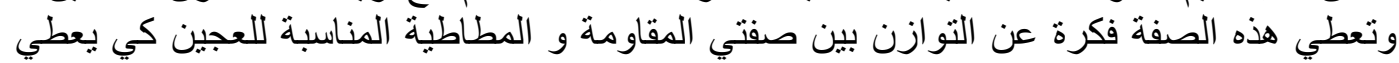




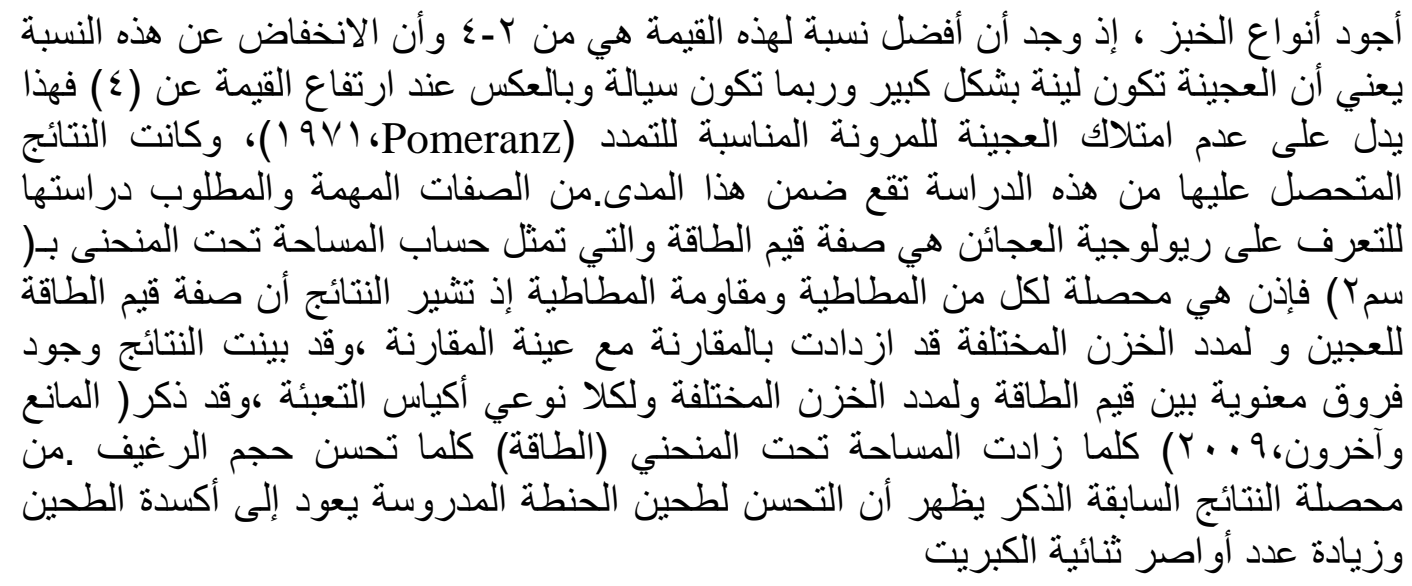

\title{
STUDY THE EFFECT OF PACKAGING MATERIALS AND STORAGE PERIOD ON RHEOLOGICAL PROPERTIES OF FLOUR
}

S.H.AL-Jbory

Coll. of Agric.and

Foresty,Mosul

Unvi.Iraq
A.Y.Hassan

General Company for Cereal

NanufacturinglNineveh

\begin{abstract}
The effect of packaging materials and storage period on rheological properties of wheat flour was studied. wheat flour was packed in polypropylene and paper sacks and stored at $30 \mathrm{C}^{\circ}$ for $30,60,90$ days. Results of amylograbh show that there were no significant $(\mathrm{P}<0.05)$ differences between initial temperature of gelatinization of flour suspension in all storage conditions. Results of farinograph show that a significant $(\mathrm{P}<0.05)$ increase in the amount of absorption water by flour stored in polypropylene, whereas there was a significant increase in the same parameter for flour stored in paper sacks for 90 days. Results also show that there were significant $(\mathrm{p}<0.05)$ differences between dough time for control flour and other samples stored in all storage conditions. The dough time was decreased and dough ripping time increased with increasing storage period, whereas dough stability time was increased with increasing storage period and critical dough coefficient was decreased with increasing storage period. The results of extensograph show that decreasing the elasticity values and increasing the elasticity resistance of flour packed in both containers with increasing storage period. This was resulted in increasing the ratio of elasticity resistance/elasticity value and increased the energy for 90 days storage period in both containers. Generally, changes in the rheological properties of the flour stored in paper sacks were less than that of stored in polypropylene sacks and there was no indication for insects infection in the flour.
\end{abstract}




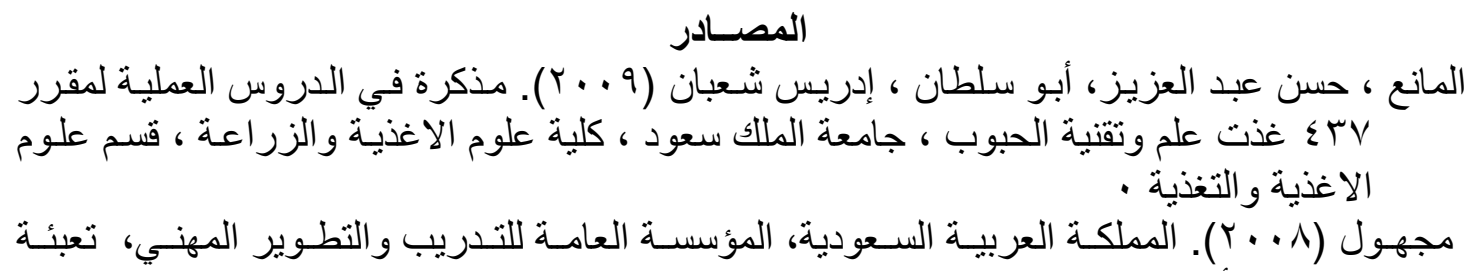

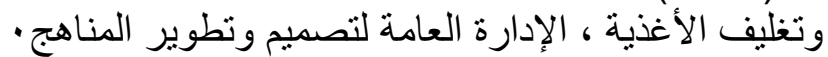

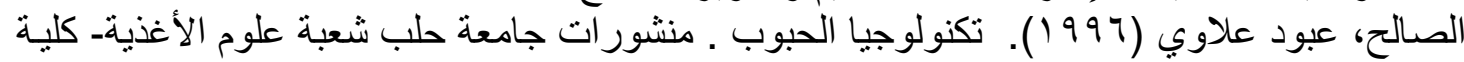

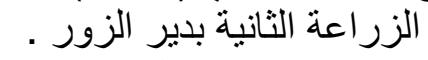

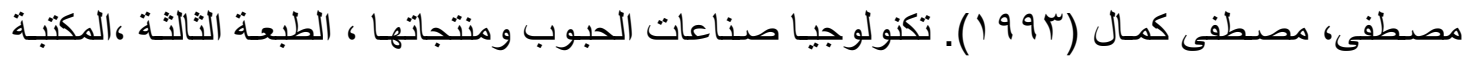

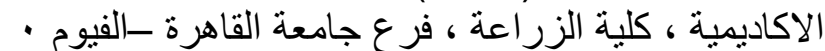

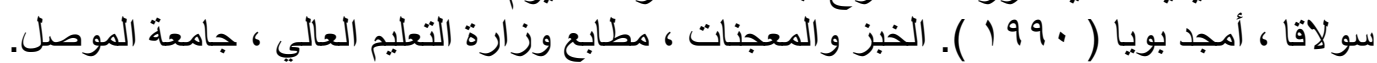

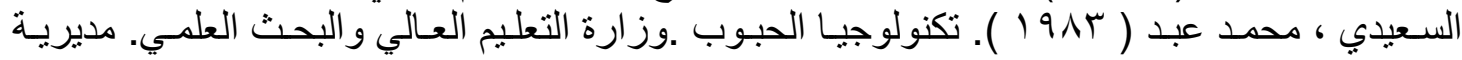

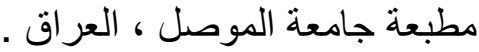

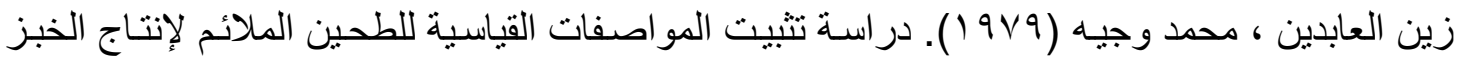

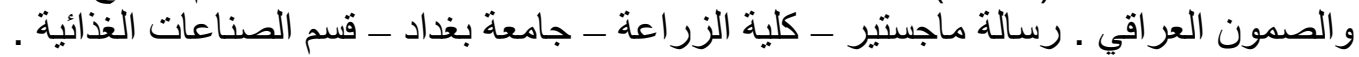

Anonymous (2000).Approved Methods of the American Association of cereal Chemists AACC, $10^{\text {th }}$ ed ; st. paul, MN.

Anonymous (2001).Statistical Analysis System Users guide. Version 7, Statistical Analysis System Institute Carry Inc. North Carolina, u. s. n.

Christensen,C.M. (1974). Storage Of Cereal Grains and Their Products ..American Associan Of Cereal Chemists St. Paul. Minn

Chung, O . K . (1986). Lipid- protein interactions in wheat flour, dough , gluten and protein fractions . cereal Foods world, $31: 242-254$.

Pietz,A. and G . L . Lookhart (1996) Properties and non-food potential of gluten . cereal Food world 41 (5) : 376-382.

Pomeranz, Y. (1971). Wheat Chemistry and Technology. Published by the American Association of Cereal Chemists. In Corporate. St. Paul. Minnesota : 217-235 .

Marie, H. andM. Dana .(2002). Changes of Wheat Flour Properties during Short Term Storage, Czech J. Food Sci.. 20,( 4): 125-130 .

Weegels, B.L.;R.Orsel;A.M.Vandepiipe Kamp;W.Jlichtendonk;R.J.Hamer and J.D.Schofield (1995).Functional properties of low $\mathrm{Mr}$ wheat proteins.Effects on dough properties .J.Cereal Sci. 21:171,126. 